\title{
Corpo e fenômeno psicossomático na clínica psicanalítica ${ }^{1}$
}

\author{
Body and psychosomatic phenomenon in clinical psychoanalysis \\ Cuerpo y fenómeno psicosomático en la clínica psicoanalítica
}

\author{
Carla Oliveira Fernandes* \\ Bruno Netto dos Reys* \\ Vera Lopes Besset ${ }^{* * *}$ \\ Marcelo Frederico Augusto dos Santos Veras ${ }^{* * *}$
}

\begin{abstract}
Resumo
O avanço da ciência e da tecnologia trouxe progressos consideráveis para o diagnóstico e o tratamento de doenças até então incuráveis. Entretanto a Medicina ainda se depara com patologias que não respondem aos tratamentos propostos. Por vezes, tendo em vista a singularidade implicada no adoecimento, a psicanálise é convocada a contribuir. No caso do fenômeno psicossomático (FPS), que se apresenta como uma lesão, a ausência de articulação ao simbólico traz dificuldades para uma abordagem clínica pautada na fala. Considerando o estatuto particular do corpo no FPS, o gozo específico suposto nessas manifestações e partindo da referência ao sintoma, este trabalho explicita as especificidades na abordagem desses casos, destacando suas implicações em um tratamento de acordo com as diretivas clínicas da psicanálise de orientação lacaniana.
\end{abstract}

Palavras-chave: Corpo. Fenômeno psicossomático. Sintoma. Clínica psicanalítica.

\begin{abstract}
The advances in science and technology have brought considerable progress to diagnosis and treatment of many diseases up to now incurable. However, medicine finds diseases that do not respond satisfactorily to proposed
\end{abstract}

Texto recebido em outubro de 2014 e aprovado para publicação em maio de 2015.

1 Este artigo está relacionado à dissertação de mestrado de Carla Oliveira Fernandes, intitulada "A psicanálise mais além do silêncio do fenômeno psicossomático" orientada pela Prof. a Dr. a Vera Lopes Besset, desenvolvida com o apoio da CAPES na Pós-Graduação em Psicologia do Instituto de Psicologia da Universidade Federal do Rio de Janeiro (UFRJ).

Doutoranda em Psicologia pelo Programa de Pós-Graduação em Psicologia do Instituto de Psicologia da UFRJ. Endereço: Rua Dr. Pedro de Souza Pondé, n. ${ }^{77}$, ap. 402 - Jardim Apipema, Salvador-BA. CEP: 40155-270. E-mail: fernandesocarla@gmail. com.

* Doutor em Psicologia pelo Programa de Pós-Graduação em Psicologia do Instituto de Psicologia da UFRJ. Endereço: Praia do Flamengo, n. ${ }^{\circ}$ 66, sala 1212, bl. B. - Flamengo, Rio de Janeiro-RJ. CEP: 22210-903. E-mail: bnreys@terra.com.br.

*** Doutora em Psicologia Aplicada pela Université Paris V (René Descartes). Docente do Programa de Pós-Graduação em Psicologia do Instituto de Psicologia da UFRJ. Endereço: Travessa Euricles de Matos, n. ${ }^{\circ} 28$ - Laranjeiras, Rio de Janeiro-RJ. CEP: 22240-010. E-mail: besset@terra.com.br.

**** Doutor em Psicologia pelo Programa de Pós-Graduação em Psicologia do Instituto de Psicologia da UFRJ, diretor da Fundação de Apoio à Pesquisa e à Extensão (Fapex). Endereço: Rua da Graviola, n.o 468, ap. 701, Salvador-BA. CEP: 41820-360. E-mail: marcelofveras@gmail.com. 
treatments. Sometimes, considering the singularity implicated in disease, psychoanalysis is called upon to contribute. An approach of psychosomatic phenomenon (PPS), which presents itself like a lesion on body, the absence of symbolic articulation brings difficulties for a clinical approach based on guided speech. Considering particular status of body at PPS, the specific jouissance of these cases and based on the reference to the symptom, this article discuss the specific approach in these cases and highlights implications for treatment according to clinical practice guidelines of Lacanian psychoanalysis.

Keywords: Body. Psychosomatic phenomenon. Symptom. Psychoanalytic clinic.

\title{
Resumen
}

El avance dela cienciay la tecnología proporcionó progresos considerables para el diagnóstico y el tratamiento de enfermedades hasta entonces incurables. Sin embargo, la medicina aún se enfrenta a patologías que no responden a los tratamientos propuestos. A veces, teniendo en cuenta la singularidad implicada en la enfermedad, el psicoanálisis es convocado a colaborar. En el caso del fenómeno psicosomático (FPS), que se presenta como una lesión, la ausencia de articulación a lo simbólico trae dificultades al enfoque clínico basado en la conversación. Considerando el estatuto particular del cuerpo en el FPS, el goce específico supuesto en estas manifestaciones y partiendo de la referencia al síntoma, este trabajo explica las especificidades en el abordaje de estos casos, destacando sus implicaciones en un tratamiento según las directivas clínicas del psicoanálisis de orientación lacaniana.

Palabras clave: Cuerpo. Fenómeno psicosomático. Síntoma. Clínica psicoanalítica.

\section{Introdução}

\begin{abstract}
0 século XIX é um marco na evolução do saber médico, momento em que a medicina busca legitimar-se pela utilização do método experimental característico das ciências físicas, o que faz com que ela possa se apresentar como medicina científica. Uma grande influência na concretização desse ideal é o trabalho do fisiologista Claude Bernard. Antes dele, no final do século XVIII, as observações de Bichat (1801), o pai da anatomopatologia moderna, são outra influência marcante. A partir daí, concebe-se que, pela localização de uma lesão histologicamente observável, a verdade da doença pode vir a ser conhecida.
\end{abstract}


Destacando a importância desse momento da constituição do saber médico, Foucault (2011) afirma ser a descoberta de Bichat "um princípio de decifração do espaço corporal que é, ao mesmo tempo, intraorgânico, interorgânico e transorgânico" (p. 140). A saúde passa a ser concebida como a vida no "silêncio dos órgãos" (Fux, 2001, p. 19), e essa concepção leva ao surgimento de novas tecnologias e práticas sobre os corpos dos indivíduos, todas pautadas em uma análise minuciosa do olhar sobre o doente. Como herança do iluminismo, a clínica médica passa a ser regida pela observação - é o olhar do médico que prevalece em detrimento do sujeito (Foucault, 2011). Em referência a esse aspecto, Lacan (2006) põe em relevo "a promoção por parte de Bichat de um olhar que se fixa no corpo nesse curto espaço de tempo donde subsiste como condenado a morte, quer dizer, o cadáver" (p. 88, tradução nossa).

Temos aí o sujeito ignorado ou excluído pela medicina, já que o paciente não tem nada a dizer sobre o mal-estar que lhe acomete. Por um "golpe de vista", o médico vê e sabe o que o doente tem, pois, ao tempo em que observa, integra cognitivamente o que vê ao conhecimento aprendido. Nessa perspectiva, a dimensão da linguagem é subtraída da cena. O saber está do lado do médico, e o paciente não tem nada a dizer sobre o que lhe ocorre, já que a subjetividade não comporta precisão. É pela observação, no lugar de objeto de investigação, um lugar passivo, que o corpo do doente é avaliado e o tratamento prescrito (Foucault, 2011).

Foucault (2011) sublinha esse aspecto quando observa que a pergunta do médico deixa de ser “o que você sente?" para “onde lhe dói?". Essa pergunta busca localizar no órgão a origem do sintoma e fecha as portas para que o paciente expresse suas fantasias sobre o que lhe ocorre. Para a medicina, portanto, o sintoma passa a responder a uma lógica meramente orgânica, é como um corpo estranho a ser eliminado.

Partindo da clínica com as pacientes histéricas, e em paralelo ao avanço da ciência médica, Freud (1893-1895/2008, v. 2) ${ }^{2}$ subverte o paradigma do sintoma como meramente orgânico. A teoria freudiana demonstra que o sintoma histérico está relacionado a uma lógica de cunho inconsciente. A conversão, por exemplo, evidencia que o corpo é atravessado pela linguagem (Besset, Zanotti, Tenenbaum, Schimidt, Fischer \& Figale, 2010). O sintoma histérico, nesse sentido, guarda com o corpo uma relação de significação, torna-se uma maneira de falar e demanda deciframento, ou seja, ele quer dizer algo, entra na conversa (Freud, 1893-1895). A anatomia em causa no sintoma histérico constitui-se como uma "anatomia fantasística" (Fux, 2001, p. 19), que não corresponde à anatomia orgânica.

2 A primeira data indica o ano de publicação original da obra, e a segunda indica a edição consultada pelo autor; que só será pontuada na primeira citação da obra no texto. Nas seguintes, será registrada apenas a data de publicação original. 
Há, com o advento da psicanálise, uma ruptura que questiona a clínica do olhar, baseada nos fenômenos observáveis, em que os pacientes são desprovidos de sua condição subjetiva. Isso dá ensejo ao surgimento de uma clínica da escuta, norteada pela ética do bem-dizer do sujeito, que porta um saber sobre seu sintoma (Montezuma, 2001). O sintoma na teoria freudiana se articula ao conceito de inconsciente, como uma instância que vem demarcar justamente a imprecisão, o fato de que o sujeito é regido por causas muitas vezes desconhecidas, apontando que "o eu não é senhor em sua própria casa" (Freud, 1917, v. 17, p. 135, tradução nossa). Para Freud, o sintoma não deve ser eliminado, mas tratado pela fala.

A partir disso, passam a existir concomitantemente duas clínicas, a do olhar e a da escuta, a clínica médica e a clínica psicanalítica. Esta última reintroduz o campo da subjetividade ao valorizar a fala do paciente, o que tinha sido deixado de lado pela medicina, com o avanço da ciência. Todavia, não se trata de uma lógica excludente, pois a psicanálise não se opõe à medicina, mas inclui o sujeito no tratamento, pondo em destaque seu dizer. $\mathrm{Na}$ abordagem dos pacientes que, com outros autores (Lacan, 1998; Guir, 1988) nomeamos "psicossomáticos", essa pode ser uma via para um tratamento possível.

Entretanto, antes de avançarmos em nossa argumentação, é necessário destacar que Freud não discorreu sobre a psicossomática em sua obra. No ensino de Lacan, encontramos formulações sobre o tema em breves passagens. Concordamos com Valas (2004), quando afirma que "isto deveria incitar os psicanalistas a serem mais prudentes no uso que fazem desse termo para qualificar manifestaçóes corporais sobre as quais se sabe muito pouco" (p. 113).

Com a sofisticação das técnicas para mapear o organismo humano, as explicações biologicistas contribuem para reduzir o psiquismo ao sistema nervoso central (Valas, 2004) e relegar a segundo plano o homem em sua dimensão de ser falante. O resultado é a medicalização da existência (Gori, Del Volgo, 2005), de modo que, se uma patologia pode ser localizada no órgão, basta a intervenção correta para revertê-la (Foucault, 2011). Em contraponto a isso, um movimento advém e cuja proposta pode ser assim resumida: “Todo adoecimento é psicossomático" (Groddeck, 2011). A psicossomática, proposta por Groddeck (2011), médico alemão contemporâneo de Freud, supunha que todas as doenças podiam ser explicadas com base no psiquismo.

Seguindo a inspiração de Groddeck, diversos autores abordam a psicossomática sob diferentes perspectivas. Dentre eles, destacamos Alexander (Alexander \& Selesnick, 1980), introdutor dos estudos de psicossomática no campo psicanalítico, e Keller (2008) cujos estudos são mais recentes. Essa teorização está na base de um psicologismo que culpabiliza o doente por sua doença 
(Sontag, 1984), excluindo outros fatores relacionados ao adoecimento. Dito de outro modo, parafraseando Exupéry (1943/2001): tu te tornas eternamente responsável pela doença que cativas. Se não souber lidar com seu sofrimento, adoecerá (Fernandes, 2014).

Partindo do pressuposto de que não há um saber que explique por completo o que está em causa no processo de adoecimento, entendendo que, entre a causa e seus efeitos, há um hiato, um não saber, objetivamos esclarecer, no bojo deste artigo, a partir da perspectiva lacaniana, de que corpo falamos quando estamos diante de pacientes com fenômenos psicossomáticos. Interessa-nos apontar uma medida comum entre medicina e psicanálise, tendo em vista que o tratamento desses pacientes não envolve uma abordagem única. Para tanto, realizamos uma revisão crítica de bibliografias que versam sobre o tema, abordando especificamente a concepção do fenômeno psicossomático e as diretivas clínicas para o tratamento.

$\mathrm{Na}$ obra freudiana, como já adiantamos, não há referência à expressão "psicossomática". Nela, o que mais se aproximaria desse termo é a ideia de uma complacência somática (somatisches Entgegenkommen). Freud (1905, v. 7, p. 110) a utiliza para falar da histeria de Dora, situando-a como uma condição para a conversão, designando-a como a "parte tomada pelo corpo no nascimento do sintoma histérico" (Kaltenbeck, 2003, p. 57). Nesse sentido, a formulação freudiana se aproxima mais da concepção do sintoma neurótico que do fenômeno que nos interessa distinguir como o mecanismo específico da lesão psicossomática.

Lacan (1998b) fala em fenômeno psicossomático elaborando uma teoria pelo viés do impacto da linguagem no ser falante. Sua primeira elaboração data de 1948, pela apresentação de um caso clínico de hipertensão arterial relacionada a uma tensão psíquica advinda de um estresse não específico (Lacan, 1948). Mas, antes de nos aprofundar nas contribuições de seu ensino ao estudo da psicossomática, é necessário distinguir sintoma e fenômeno psicossomático (FPS). Por serem de ordens distintas, essas manifestaçôes no corpo implicam especificidades na direção do tratamento.

\section{Sintoma e fenômeno psicossomático}

Podemos considerar o sintoma, de acordo com a obra freudiana, como metáfora, decifrável a partir da interpretação do analista e como satisfação pulsional, que garante um ganho primário, com um núcleo inacessível à interpretação, irredutível à ordem significante (Miller, 2008a). Diferentemente do sintoma, o fenômeno psicossomático não opera de acordo com essa lógica. 
No FPS, há um substrato orgânico, uma lesão, é como se houvesse um curtocircuito no processo de subjetivação que recai no corpo (Monribot, 2008; García-Romero, 2013).

O sintoma porta em si uma mensagem que tem um valor de verdade para o sujeito, revelando o que é da ordem de seu desejo e de seu modo de gozo. Assim, pode entrar na cadeia significante e, a partir daí, ser simbolizado pela palavra, advindo como efeito a redução do sofrimento em questão. Já o FPS não se articula à cadeia significante por se constituir de outro modo: "Ele se repete em impulsos periódicos, como pulsações de gozo" (Valas, 2004, p. 120). Enquanto o sintoma pode ser reduzido ou, muitas vezes, sanado "em uma análise linguageira, por ser ele mesmo estruturado como uma linguagem” (Lacan, 1998a, p. 270), isso não ocorre no caso de pacientes com fenômenos psicossomáticos.

No FPS não entra em jogo a articulação significante, como no sintoma (Merlet, 2002). O mecanismo que predomina foi definido por Lacan (1998c) como indução significante: "A psicossomática é algo que não é um significante, mas que, mesmo assim, só é concebível na medida em que a indução significante, no nível do sujeito, se passou de maneira que não põe em jogo a afânise do sujeito" (p. 215).

Para explicar o mecanismo em jogo na indução significante, Lacan (1998c) utiliza-se do experimento pavloviano que, em linhas gerais, opera de acordo com o seguinte procedimento: o experimentador faz um cachorro ouvir o som de uma campainha ao mesmo tempo em que lhe fornece alimento e, assim, repete diversas vezes até condicionar o animal. Em um determinado momento, passa a emitir o estímulo sonoro sem oferecer comida, e cada vez que o cachorro ouve o som, produz secreção gástrica, o que culmina em uma úlcera.

\footnotetext{
Uma vez que vocês fazem secretar seu cão a vista de um pedaço de carne, o que lhes interessa, a partir daí, é recortar a coisa na região da secreção salivar e mostrar que esta é articulável com algo que funciona como significante, pois que feita pelo experimentador. Em outros termos, aí está o Outro (Lacan, 1998c, p. 216).
}

Lacan (1998c) considera que o som funciona como um significante que, associado à necessidade de comer, induz a produção de secreção gástrica. Desse modo, o desejo do Outro (experimentador) repercute, por indução significante, em uma lesão corporal. Assim, podemos entender que, enquanto o sintoma neurótico é uma defesa do sujeito frente ao desejo do Outro, as lesões psicossomáticas se produzem para além da subjetividade, no corpo condicionado 
e sem defesa (Valas, 2004). Dito de outro modo, se o sintoma envolve uma construção do sujeito em torno da pergunta sobre quem ele é no desejo do Outro, a lesão psicossomática é um fenômeno que comporta uma fixação de gozo diante de imperativos superegoicos do Outro (Valas, 2004), sem possibilidade de formular uma pergunta para tentar traduzi-los.

Encontramos em Miller (2003) uma especificação do FPS em referência ao sintoma. Esse autor afirma que o FPS "nos dá, em primeiro lugar, uma forma de ataque de metáfora subjetiva que é a ausência de afânise - holófrase, gelificação, etc., e, em segundo lugar, um ataque da metáfora paterna, pondo em questão o pai, o Nome-do-pai, o pai do nome, etc.” (p. 88). É justamente a relação ao Outro, constitutiva do sintoma histérico, que está ausente no FPS, o que levou Lacan a situar o FPS "quase no registro do animal do homem" (p. 89). É importante destacar que não se trata de uma estrutura específica, mas de um fenômeno que pode se apresentar em qualquer uma das três estruturas: psicose, neurose ou perversão. Podemos pensar o FPS como uma resposta singular no corpo a uma contingência específica.

Outro ponto importante a esclarecer é a relação entre FPS e angústia, pois existe uma tendência a explicar que o estresse como resposta a eventos estressores é a causa do adoecimento nos casos de pessoas que apresentam lesóes psicossomáticas. De acordo com Monribot (2008), temos aqui exatamente o contrário: o FPS ocorre quando justamente não é possível responder desse modo. Ou seja, não é uma angústia excessiva que causa um problema somático, mas a ausência da possibilidade de angústia para um sujeito, já que a angústia surgiria justamente como uma defesa contra o real.

É quando a dimensão subjetiva não entra em cena diante de um evento traumático que pode surgir um FPS (García-Romero, 2013). Trata-se de uma fixação de gozo silenciosa e específica, como propõe Lacan (1998d). A atividade pulsional é acompanhada de silêncio em sua dimensão mais radical, sem a possibilidade de simbolização. Lacan (1998d) afirma ser o FPS da ordem de uma escrita ilegível, como um hieróglifo no deserto: "Tudo se passa como se algo estivesse escrito no corpo, alguma coisa que se oferece como um enigma" (p. 13-14).

Lacan escreve a estrutura da linguagem a partir da cadeia significante, mais especificamente da sua unidade mínima, como assinalado pelo matema S1-S2. Assim, para que se produza o efeito a que chamamos sujeito, são necessários no mínimo dois significantes, ou seja, um par opositivo, que grafamos como S1-S2. Assim, um significante (S1) pode representar um sujeito (\$) para outro significante (S2). Segundo Miller (2003), no FPS encontramos um S1 absoluto, 
não dialetizável em relação a um S2 e, portanto, não representando nada. Assim, há como um congelamento, um apagamento do intervalo entre S1 e S2, formando uma holófrase, uma colagem entre S1 e S2 (S1S2) que se torna um novo $S 1$, hipertrofiado, absoluto, não dialetizável e excêntrico em relação à estrutura da linguagem.

Enquanto no sintoma histérico a relação com o Outro é constitutiva, no FPS há um contorno do Outro do significante, do Outro do desejo, mas, nesse golpe, o corpo é tomado como Outro. Como efeito, a libido deixa de ser, como na histeria, um órgão incorpóreo, para se tornar ela mesma corporificada (Miller, 2003). A operação significante que denominamos holófrase, no caso do FPS, consiste numa inscrição que produz um efeito no real do corpo, mas cujo sentido é mudo, tornando-se então uma inscrição, ou uma escrita ilegível, como o traduz a metáfora lacaniana do hieróglifo no deserto (Lacan, 1998d).

Diante do FPS, nós nos deparamos com uma escrita cifrada, ou uma escrita de cifras: "O corpo no significante faz traço, e traço que é um Um [...] é ao redor do traço unário que circula toda a questão do escrito. Que o hieróglifo seja egípcio ou chinês dá no mesmo. Trata-se sempre de uma configuração do traço" (Lacan, 1998d, p. 25). Por isso, dada essa ausência de sentido do lado do FPS, Lacan (1998d) busca aproximá-lo do número, mais do que da letra, situada mais próxima do campo simbólico, pois o número está situado no terreno do real (Miller, 2003).

A partir daí, Lacan (1998d) se pergunta qual a espécie de gozo que encontramos no FPS e explica que se trata de uma fixação (Fixierung), de um gozo "gelificado", sendo "pela revelação do gozo específico que há na sua fixação, que é preciso sempre visar a abordar o psicossomático... (que está) no seu fundamento, profundamente arraigado no imaginário" (p. 14). Podemos dizer que a holófrase é uma escrita que se inscreve no corpo, repercutindo na lesão. Trata-se de um curto-circuito significante que imprime uma marca no corpo (Guir, 1988). Mas que corpo é esse que se apresenta em pacientes com fenômenos psicossomáticos?

\section{O estatuto do corpo no fenômeno psicossomático}

Concordamos com Miller (2004), em Biologia Lacaniana, quando afirma que, para a psicanálise, em relação ao corpo,

Não se trata, somente, do corpo imaginário, do corpo sob a sua forma. Não se trata do corpo-imagem, desse que conhecemos, ao qual nos referimos, porque opera no estádio do espelho, esse corpo especular que duplica o organismo. Não se trata, também, do corpo simbólico, aquele que, recorrentemente, faz vir, sob a pena de Lacan, a metáfora do brasão (p. 14). 
Estamos diante da questão de um corpo afetado pelo gozo, que tem como causa o significante, a partir do momento em que está inserido na linguagem.

Lacan, ao longo de seu ensino, destaca a diferença entre ser um corpo e ter um corpo. Para Lacan (2007), ter um corpo implica em fazer uso dele: "O falasser adora seu corpo, porque crê que o tem. Na realidade, ele não o tem, mas seu corpo é sua única consistência, consistência mental, é claro, pois seu corpo sai fora a todo instante" (p. 64). O neurótico acredita que tem um corpo, mas isso pode ser abalado quando advém angústia e o sujeito suspeita reduzir-se ao seu corpo (Lacan, 2011). Diferentemente do que ocorre na psicose esquizofrênica, por exemplo, na qual o fato de ser um corpo, um corpo fragmentado, se impóe constantemente. Para além da estrutura clínica, podemos pensar que, no FPS, o sujeito se depara com um corpo imposto, apresentado, e não representado (Queiroz, 2008).

Partindo dos três registros da experiência do ser falante, real, simbólico e imaginário, Monribot (2008) considera que, nesses casos, há uma aderência do imaginário ao real por meio da lesão. Trata-se de pacientes que, diante do encontro com o real, em vez de responder com um sintoma, uma inibição ou produzir angústia, desencadeiam uma lesão. Para Miller (2008b), no FPS há uma prevalência da superfície do corpo no lugar de fazer passar o gozo ao inconsciente, ao sintoma. Assim, há uma fixação de gozo no corpo, sem o respaldo da fantasia fundamental como amparo para fazer um ponto de basta. Caberia ao analista operar justamente no nível do gozo.

Mas como passar do hieróglifo no deserto à leitura e tratamento pela fala na clínica? Para Lacan (1998d), a direção do tratamento está em viabilizar a representação desse gozo silencioso do FPS. É interessante destacar que a escrita hieroglífica pode ser escrita em linhas ou colunas, em qualquer direção. Para identificar a direção de leitura de um determinado texto, deve-se analisar para onde os sinais estão voltados. Uma lição para a clínica do FPS: é preciso se descolar do sentido para ler a holófrase de outras formas, a homofonia que produz, o congelamento de significantes que comporta no intuito de desmembrá-los (Fernandes, 2014).

\section{Ler o fenômeno psicossomático na clínica}

$\mathrm{Na}$ clínica do FPS, como lidamos com pacientes que ficam absorvidos pelas lesões, que adquirem protagonismo em suas falas, é fundamental considerar a possibilidade de um "distanciamento simbólico" nas entrevistas preliminares (Guir, 1988, p. 27-28). É necessário estarmos atentos aos termos que surgem nas sessões, pois o significante nos fornece índices preciosos sobre o FPS. É 
remetendo esses nomes à cadeia significante que é possível fazer de uma lesão imposta um enigma, transformá-la em sintoma para o sujeito, operando assim na passagem do gozo ao desejo (Liart, 2012; Monribot, 2008).

Para Monribot (2008), nos casos de estrutura neurótica, a direção do tratamento deve visar ao desmembramento da holófrase no percurso da análise, fragmentando a escrita que se impõe ao sujeito. $\mathrm{O}$ autor indica, baseado em um caso clínico de um paciente com rinite alérgica crônica, como operar nessa direção.

Vejamos um trecho do caso: um adulto diz em análise que começou a apresentar uma alergia severa após sua primeira relação sexual, aos 15 anos. Antes disso, aos 11 anos, após assistir ao pai ferir o olho em um pedaço de madeira, começou com um tique de arregalar os olhos. Após sua primeira relação sexual, o tique cessou, mas em seu lugar surgiu a rinite.

$\mathrm{Na}$ análise, o paciente rememorou uma cena de quando tinha em torno de 3 anos, que adveio como uma imagem congelada: pela fechadura da porta, viu sua mãe tocando e cuidando do pênis de seu pai, que estava ferido. Ela tinha nas mãos um frasco de mercúrio cromo, em francês, mercurochrome, que utilizava na ferida. Na direção do tratamento, esse evento teve valor de cena primária. Há o olhar da criança, que remete ao traço voyeurista da fantasia, há o pênis ferido do pai, que remete à castração, e o papel da mãe nessa relação com o pai.

Esses elementos são objeto de trabalho na análise. O termo mercurochrome, que o analista considera com valor de holófrase, procedendo à decomposição das palavras que estavam holofraseadas: mère-cure-ocre-homme. Traduzindo para o português, podemos decompor essa holófrase como mãe-cura-ocre-homem. $\mathrm{O}$ termo ocre resta como um significante bizarro, que não tem sentido particular. Após esse descongelamento, por assim dizer, os significantes que emergem na cadeia significante podem ser tratados pela palavra e, com isso, o embate do paciente contra a rinite alérgica cessa.

Trata-se de um esforço de interpretação por parte do analista que permite o tratamento pela fala de um gozo fixado na lesão. Diferentemente de um sintoma, que implica na passagem do gozo ao inconsciente, o fenômeno psicossomático não quer dizer nada para ninguém. Como afirma Miller (2008b), no FPS estamos diante de uma manifestação que está bem próxima do real, por isso Lacan (1975/1998) fala disso fazendo referência a um fenômeno que é da ordem do hieróglifo, do número e não da letra, como o sintoma.

Monribot (2008) explica que, diante da impossibilidade de representação da cena traumática, que punha em jogo um gozo da imagem, o sujeito fica 
"petrificado" (p. 20), sem possibilidade de metaforizar o que vê. Diante da primeira relação sexual, a cena primária foi evocada, o sujeito se depara com a holófrase da cena infantil e a rinite alérgica se instala. O tique, que havia cessado, no percurso da análise, com a contingência de ser pai, retorna. $\mathrm{O}$ analista então dá ao tique o estatuto de sintoma, com valor de metáfora, por colocar em órbita o pai fora de órbita, impotente. É preciso destacar que a mãe do paciente se referia ao tique do filho como exorbitante, fora de órbita. Percebemos, nesse caso clínico, que o falasser produz um FPS quando não há recurso simbólico para produzir um sintoma.

Nesses casos, é necessário saber ler no discurso do paciente o que aparece como holófrase. Para Miller (2011), saber ler aponta para o momento inicial de condensação de gozo, que é como um clinâmen. $\mathrm{O}$ autor explica que esse é um termo da Filosofia, proposto por Epicuro, para explicar a contingência da colisão atômica que repercute na constituição dos seres vivos e da natureza.

$\mathrm{Na}$ direção do tratamento, é preciso localizar o clinâmen do gozo, o momento contingente do congelamento de significantes holofraseados no corpo, que repercute na constituição do fenômeno psicossomático. Podemos supor, com o último ensino de Lacan, que há uma passagem de uma clínica centrada na escuta do sentido do sintoma, para uma clínica da leitura, pois se trata de ler, nas ressonâncias da fala do paciente, o que se inscreve como escrita de gozo. Os casos de pacientes com fenômenos psicossomáticos nos ensinam sobre essa clínica, uma clínica onde prevalece um modo de gozo circunscrito no corpo, refratário ao simbólico. Trata-se de fazer falar o corpo (Miller, 2014), tendo no horizonte, é claro, a função que essa inscrição ocupa na vida de cada paciente.

\section{Considerações finais}

Vemos assim, como procuramos evidenciar com o presente trabalho, que é fundamental para a abordagem clínica do FPS, dentro da orientação psicanalítica lacaniana, distingui-lo do que entendemos especificamente por sintoma, quando tomamos o sintoma histérico como paradigma, em sua interface com o real da satisfação e o simbólico, sendo assim passível de interpretação. Essa perspectiva difere radicalmente daquela dos pioneiros da abordagem psicanalítica do FPS (Alexander \& Selesnick, 1980; Groddeck, 2011).

Para nós, FPS e sintoma distinguem-se radicalmente um do outro conforme o FPS se encontra fora do jogo da articulação significante e, por conseguinte, da emergência do sentido; por sua estrutura holofraseada, não se presta à interpretação. Assim, a tarefa analítica consiste, como indicam os dados clínicos abordados, em ler a holófrase implicada no FPS, estando atento para as 
singularidades de cada caso. No caso de uma psicose, por exemplo, é preciso ter cautela, pois o FPS pode cumprir uma função na vida desse paciente.

Além disso, é importante destacar que, no caso de tais fenômenos, estamos diante de um gozo específico, de um corpo marcado pela holófrase no real, como uma assinatura ou uma tatuagem indecifráveis, daí o fato de ter uma lesão correspondente. A perspectiva, aqui, é a do tratamento aliado à medicina, sempre que necessário. À condição, evidentemente, do respeito à especificidade de cada uma dessas abordagens. A partir do último ensino de Lacan, podemos considerar o fenômeno psicossomático como um modo de adoecer passível de ser abordado pela psicanálise, assumindo no horizonte o direcionamento ao real. 


\section{Referências}

Alexander, F. \& Selesnick, S. T. (1980). História da psiquiatria: uma avaliação do pensamento e da prática psiquiátrica desde os tempos primitivos até o presente. São Paulo: Ibrasa.

Besset, V. L, Zanotti, S. V., Tenenbaum, D., Schimidt, N., Fischer, R. \& Figale, V. (2010). Corpo e histeria: atualizações sobre a dor. Polêmica, 9(4), 35-42.

Bichat, X. (1801). Anatomie générale, appliquée à la physiologie et la médecine. (Vol. 1-2). Paris: Brosson, Gabon et $\mathrm{C}^{\mathrm{ie}}$. Recuperado a partir de: http://gallica. bnf.fr/ark:/12148/bpt6k98766m

Exupéry, A. S. (1943). O pequeno principe. (48a ed.). Rio de Janeiro: Agir, 2001. (Publicado originalmente em 1943).

Fernandes, C. O. (2014). A psicanálise mais além do silêncio do fenômeno psicossomático. (Dissertação de mestrado). Universidade Federal do Rio de Janeiro, Programa de Pós-graduação em Psicologia, Rio de Janeiro. Recuperado a partir de http://objdig.ufrj.br/30/teses/814698.pdf.

Foucault, M. (2011). O nascimento da clínica. Rio de Janeiro: Forense Universitária. (Publicado originalmente em 1980).

Freud, S. (1893-1895). Estudios sobre la histeria (Breuer y Freud). In Obras Completas. (Vol. 2, pp. 1-342). Buenos Aires: Amorrortu, 2008. (Publicado originalmente em 1893-1895).

Freud, S. (1905). Fragmento de análisis de un caso de histeria. In Obras Completas. (Vol. 7, pp. 1-107). Buenos Aires: Amorrortu, 2008. (Publicado originalmente em 1905[1901]).

Freud, S. (1917). Una dificultad del psicoanálisis. In Obras Completas. (Vol. 17, pp. 125-135). Buenos Aires: Amorrortu, 2008c. (Publicado originalmente em 1917).

Fux, S. P. (2001). Psicossomática: uma questão para a psicanálise. Correio Revista da Escola Brasileira de Psicanálise, 35, 18-27.

García-Romero, A. F. (2013). El fenómeno psicosomático, entre la medicina y el psicoanálisis. In: Cárdenas, M. H. Bitácora lacaniana 2: satisfacciones del cuerpo. (pp. 107-114). Olivos: Grama.

Gori, R., Del Volgo, M. J. (2005). La santé totalitaire: essai sur la médicalisation 
de l'existence. Paris: Denoël.

Groddeck, G. (2011). Estudos psicanalíticos sobre psicossomática. São Paulo: Perspectiva.

Guir, J. (1988). A psicossomática na clínica lacaniana. Rio de Janeiro: Jorge Zahar.

Kaltenbeck, F. (2003) A complacência somática. In R. Wartel, A. Merlet, E. Laurent, M-H Blancard, F. Joselin, J. Guir, ... J-A. Miller (Org.), Psicossomática e psicanálise. (pp. 57-67). Rio de Janeiro: Jorge Zahar.

Keller, P.-H. (2008). La question psychosomatique. Paris: Dunod.

Lacan, J (1948). Essai sur les réactions psychiques de l'hypertendu. Annales médico-chirurgicales. (pp. 171-176). Paris: Masson.

Lacan, J. (1998a). Função e campo da fala e da linguagem e psicanálise. In Escritos. (pp. 238-324). Rio de Janeiro: Jorge Zahar.

Lacan, J. (1998b). O Seminário - livro 3: as psicoses. Rio de Janeiro: Jorge Zahar.

Lacan, J. (1998c). O Seminário - livro 11: os quatro conceitos fundamentais da psicanálise. Rio de Janeiro: Jorge Zahar.

Lacan, J. (1998d). Conferência em Genebra sobre o sintoma. Opção Lacaniana, 23, 6-16.

Lacan, J. (2006). Psicoanalisis y medicina. In J. Lacan. Intervenciones y textos 1. (pp. 86-99). Buenos Aires: Manantial. (Publicado originalmente em 1966).

Lacan, J. (2007). O Seminário - livro 23: o sinthoma. Rio de Janeiro: Jorge Zahar.

Lacan, J. (2011). A terceira. Intervenção no VII Congresso da Escola Freudiana de Paris. Opção Lacaniana, 62, 11-36.

Liart, M. (2012). Psychanalyse et psychosomatique: le corps et l'ecrit. Paris: L'Harmattan.

Merlet, A. (2002). Les phénomènes psychosomatiques. Le Pont Freundien. Recuperado a partir de http://pontfreudien.org/content/alain-merlet-lesph\%C3\%A9nom\%C3\%A8nes-psychosomatiques

Miller, J. -A. (2003). Algumas reflexões sobre o fenômeno psicossomático. In Roger Wartel et al. (Org.), Psicossomática e psicanálise. (pp. 87-97). Rio de 
Janeiro: Jorge Zahar.

Miller, J. A. (2004). Biologia lacaniana e acontecimentos de corpo. Opção Lacaniana, 41, 9-24.

Miller, J. A. (2008a). El partenaire-síntoma. (pp. 53-71). Buenos Aires: Paidós. (Colección: Los Cursos Psicoanalíticos de Jacques-Alain Miller)

Miller, J. A. (2008b). Nous sommes tous dês phénomènes psychossomatiques. Cahiers Psychanalytiques de l'Est. Automne, 13, 7-14.

Miller, J. A. (2011). Ler um sintoma. São Paulo: Escola brasileira de psicanálise. Recuperado a partir de http://www.ebpsp.org.br/index.php?option=com content $\&$ view=article $\&$ id $=579$ :ler-um-sintoma-jacques-alain- miller $\&$ catid $=2$ 3: textos\&Itemid $=54$

Miller J.A. (2014). L'inconscient et le corps parlant. La Cause du désir, 88, 104114.

Monribot, P. (2008). Qu'est-ce que la psychossomatique? Aperçus psychanalytiques. Cahiers Psychanalytiques de l'Est. Automne, 13, 15-26.

Montezuma, M. A. (2001). A clínica na saúde mental. In Antônio Quinet (Org.), Psicanálise e psiquiatria: controvérsias e convergências. Rio de Janeiro: Rios Ambiciosos.

Queiroz, E. F. (2008). O inconsciente é psicossomático. Revista Mal-Estar e Subjetividade, 8(4), 911-924. Recuperado a partir de http://pepsic.bvsalud. org/pdf/malestar/v8n4/04.pdf

Sontag, S. (1984). A doença como metáfora. Rio de Janeiro: Graal.

Valas, P. (2004). Um fetiche para ignorantes: a psicossomática. O corpo do outro e a criança, 6(33), 113-126. 